\title{
DISTRIBUIÇÃO SOCIAL DO LÉXICO DIALÉTICO NA CIDADE DE MÁLAGA. REFLEXÕES SOBRE A UTILIDADE DO USO DE DIALETISMOS EM SALA DE AULA DE LÍNGUAS ESTRANGEIRAS
}

\author{
DISTRIBUCIÓN SOCIAL DEL LÉXICO DIALECTAL EN LA CIUDAD DE MÁLAGA. \\ REFLEXIONES EN TORNO A LA UTILIDAD DEL EMPLEO DE DIALECTALISMOS \\ EN EL AULA DE LENGUAS EXTRANJERAS
}

\author{
SOCIAL DISTRIBUTION OF THE DIALECTAL LEXICON IN THE CITY OF \\ MALAGA. ABOUT THE UTILITY OF DIALECTALISM EMPLOYMENT IN THE \\ FOREIGN LANGUAGE CLASS
}

\author{
Antonio Manuel ÁVILA MUÑOZ ${ }^{1}$
}

\begin{abstract}
RESUMO: Estando constatada a validade do uso do léxico de proximidade (dialetalismos, regionalismos e localismos) dentro das salas de aula de línguas estrangeiras como uma ferramenta para a integração social das populações imigrantes em risco de exclusão (Ávila, 2019, a, b), com este trabalho analisamos a distribuição dos dialetalismos presentes no banco de dados do Proyecto de Estudio de los Condicionamientos Sociales del Léxico Disponible en la Ciudad de Málaga (Projeto CONSOLEX). O perfil social das pessoas que mais atualizaram os dialetalismos nas suas listas de disponibilidade lexical coincide com uma mulher de 54 anos ou mais, com uma formação média ou superior de estudos e com fortes raízes nas tradições vernaculares. A participação voluntária dessas pessoas em apoio ao corpo docente de línguas estrangeiras para as populações mencionadas poderia contribuir para melhorar a qualidade do modelo de integração proposto.
\end{abstract}

PALAVRAS-CHAVE: Léxico disponível. Distribuição social do léxico local. Inclusão social. Ensino de línguas estrangeiras. Sociolinguística.

RESUMEN: Una vez demostrada la eficacia del empleo de léxico de proximidad (dialectalismos, regionalismos, localismos) en el aula de lenguas extranjeras como herramienta de integración social de poblaciones migrantes en riesgo de exclusión (Ávila, $2019 a$, b), con el presente trabajo analizamos la distribución social de los dialectalismos contenidos en la base de datos del Proyecto de Estudio de los Condicionamientos Sociales del Léxico Disponible en la Ciudad de Málaga (Proyecto CONSOLEX). El perfil social de las personas que más emplearon dialectalismos en sus listas de disponibilidad léxica se corresponde con una mujer mayor de 54 años, con estudios medios o superiores y fuerte arraigo a las tradiciones vernaculares. Contar con la participación voluntaria de estas personas como apoyo al profesorado de lenguas extranjeras para las poblaciones citadas podría contribuir a mejorar la eficacia del modelo de integración propuesto.

PALABRAS CLAVE: Léxico disponible. Distribución social del léxico dialectal. Inclusión social. Enseñanza de lenguas extranjeras. Sociolingüística.

${ }^{1}$ Universidad de Málaga (UMA), Teatinos - Málaga - España. Profesor Titular de Lingüística General. Doctor en Filología Hispánica (UMA). ORCID: https://orcid.org/0000-0002-5239-2670. Correo: amavila@uma.es 
ABSTRACT: In previous work, we proved the effectiveness of teaching "proximity lexicon" (i.e. dialectal, regional or local words) in foreign language classrooms as a tool for the migrants' better integration - particularly those at risk of social exclusion (Avila, 2019a, b) -. The present paper analyses the social variation of dialect words collected during the Project on the Social Stratification of Available Lexicon in Malaga City (CONSOLEXProject). The potential users of dialectalisms, as reflected in their available lexicon lists, were secondary or university female speakers older than 54 years who are strongly attached to vernacular values and traditions. Volunteering contribution by this specific sort of people would help foreign language teachers improve their understanding and organize better social integration syllabuses for migrants.

KEYWORDS: Available lexicón. Social distribution of dialectalisms. Social inclusion. Teaching foreign languages. Sociolinguistics.

\section{Introdução}

Apesar de a pesquisa teórica em sociolinguística tenha consolidado uma autonomia importante, essa disciplina sempre mostrou uma vocação natural para proporcionar soluções objetivas e reais para os problemas sociais mais próximos (Labov, Shuy). A missão terapêutica ou emancipatória da sociolingüística aplicada a situações de conflito e desigualdade social, dependendo do caso, pode chegar a iludir, principalmente ao abordar questões cruciais no momento histórico em que vivemos (BOURDIEU 1984; SANKOFF, 1988; WILLIAMS 1992; VILLENA, 1992). Uma dessas questões refere-se à necessidade de facilitar a adaptação e integração de milhões de migrantes que se veem forçados a abandonar seus países de origem para buscar melhores condições de vida fora de seus lares. Embora os movimentos migratórios tenham sido constantes ao longo da história da humanidade, as migrações se tornaram mais evidentes no século XXI, devido a uma situação turbulenta e instável em grandes áreas geográficas que origina e justifica a necessidade de procurar novas oportunidades em diferentes países. As sociedades anfitriãs, em geral, fazem esforços notáveis para se adaptar à situação, ainda que, ao mesmo tempo, surjam nessas comunidades opiniões, propostas e movimentos, que geram certa aversão aos migrantes e ganham cada vez mais adeptos, se observarmos a profundidade que determinados discursos xenófobos parecem ter em alguns grupos sociais. Longe de entrar em questões políticas ou ideológicas, além do escopo da pesquisa em questão, este artigo visa contribuir para melhorar e promover o bemestar de grupos de migrantes em risco de vulnerabilidade e exclusão social.

Nossa proposta tem origem no campo de estudos da sociolinguística aplicada ao ensino de línguas estrangeiras. Especificamente, queremos conhecer a estratificação social por trás do uso do léxico local (regional, provincial, local) nas comunidades anfitriãs de 
migrantes. A eficácia do emprego de dialetalismos na sala de aula de língua estrangeira como ferramenta de integração social foi recentemente demonstrada tanto do ponto de vista teórico (ÁVILA, 2019a) quanto prático (ÁVILA, 2019b). Por um lado, no primeiro desses trabalhos, foi proposto um sistema de ensino de idiomas que afetava a seleção apropriada do componente lexical com base em um modelo de coroas. A originalidade da proposta consistiu na inclusão de um nível específico dedicado aos elementos de proximidade, cuja função era conseguir a integração dos migrantes em situações de risco de exclusão social. Por outro lado, no segundo trabalho citado, demonstrou-se a eficácia do dito modelo como uma ferramenta de integração baseada em sua real aplicação em sala de aula de espanhol como língua estrangeira com estudantes em situação de vulnerabilidade social (refugiados, exilados, migrantes em geral. Nesse experimento, o índice de bem-estar vital dos informantes foi controlado por meio de um questionário ad hoc que levou a resultados muito encorajadores quanto à eficácia da proposta: de maneira altamente significativa em todas as variáveis analisadas, a percepção dos entrevistados em relação à sua integração social e sua satisfação com a vida era muito alta. Esses dados foram contrastados com os obtidos em um grupo de controle, em que as condições do experimento eram idênticas, à exceção de que a proposta baseada no ensino do vocabulário de proximidade não foi aplicada a eles. As diferenças encontradas entre os dois grupos foram altamente significativas e estatisticamente relevantes.

As características do léxico de proximidade foram analisadas em um trabalho anterior (ÁVILA, 2017b), em que foi exposta a simplicidade morfológica desse termo, quase sempre resultado da sufixação ou prefixação de estruturas existentes no espanhol geral que, devido às condições contextuais e experienciais da comunidade de fala estudada, adquire matizes específicos. Devido à sua simplicidade estrutural, esse conjunto de léxico parecia ideal para usarmos na sala de aula de ensino de línguas estrangeiras, especialmente ao trabalhar com os níveis inicial ou intermediário (ÁVILA, 2017a, p. 551-552).

No entanto, ainda resta verifica como é estratificado em comunidades nativas o léxico local. Consideramos que acessar tal informação é essencial para entender a eficácia desta ferramenta e explorar plenamente suas possibilidades como veículo de integração social. Se soubermos quais grupos sociais promovem seu emprego, podemos procurá-los em busca de informações, assessoria, colaboração e apoio na tarefa necessária para alcançar a plena integração dos alunos de segunda língua em risco de exclusão social. 


\section{Objetivos e hipótese}

Nosso principal objetivo é conhecer e entender os refúgios sociais da conservação do léxico dialetal. Com essas informações, tentaremos melhorar as propostas anteriores para o uso de dialetos como uma ferramenta de inclusão social para grupos socialmente vulneráveis na sala de aula de língua estrangeira. Vamos analisar as listas de léxico dialetal contidas no corpus geral do Projeto Condições Sociais do Léxico Disponível na cidade de Málaga (Projeto CONSOLEX). Como já temos uma primeira aproximação de sua estrutura (ÁVILA; VILLENA, 2010), agora enriquecemos consideravelmente as informações contidas no banco de dados, graças a uma análise mais minuciosa de cada uma das 24.634 formas que a compõem. Ao dispor de um banco de dados sociológico associado ao corpus do léxico, conseguimos identificar as variáveis sociais que favorecem a conservação do léxico dialetal na comunidade estudada.

A maioria das variedades linguísticas do espanhol falado nas áreas urbanas mais estudadas Andaluzia orienta (Granada, Málaga) mostra um processo de convergência para o padrão nacional e, portanto, para o abandono de estruturas que, em outros tempos, refletiam um certo grau de identidade regional frente a outras variedades linguísticas (VILLENA; ÁVILA, 2012). Nesse contexto, o componente lexical acaba sendo um excelente laboratório de observação, no qual se verifica a substituição progressiva de formas consideradas regionais, provinciais ou locais, a partir de um processo de nivelamento e simplificação do léxico dialético em direção a formas cada vez mais padronizadas. Esse fenômeno promove o aparecimento de uma variedade neutra, em que variantes marcadas diatopicamente são progressivamente substituídas por outras pertencentes ao escopo do léxico geral. No entanto, a confirmação desse processo dinâmico de convergência revela outro fenômeno que deriva dele: a conservação de elementos divergentes por certos grupos sociais nos quais eles são mantidos com notável vigor e função.

Embora seja verdade que as listas de disponibilidade lexical geralmente não contenham um grande número de dialetalismos entre suas formas, a comparação dos resultados obtidos em estudos anteriores com os aqui apresentados poderia supor evidências adicionais desse fenômeno dinâmico de convergência de dialetos observado na cidade de Málaga, especialmente nas classes média-alta da juventude urbana (VILLENA, 2008). Ao mesmo tempo, o fenômeno divergente parece ter uma raiz significativa nos grupos sociais de clase média-baixa de idade avançada (ÁVILA, 2017b). 
A escassa ocorrência de variantes regionais nas listas de disponibilidade lexical devese principalmente a questões de orden metodológicas: por um lado, os testes são realizados em um ambiente altamente formalizado pouco propício ao aparecimento do léxico dialetal; por outro lado, alguns dos campos de experiência propostos aos informantes para a ativação das listas de disponibilidade não favorecem a atualização de variantes lexicais desse tipo, debido a seu caráter ambíguo. Acreditamos que a nova perspectiva que contribuímos neste trabalho em relação à escassa ocorrência de dialetalismos nas listas de disponibilidade supõe uma nova dimensão de estudo relacionada às seguintes hipóteses:

1. A convergência linguística das variedades do sul da Espanha, no sentido dos dialetos regionais centrais e da variedade padrão comprovada em outros níveis de análise, manifesta-se fortemente no componente lexical.

2. Isso ocorre porque as ocorrências de léxico dialetal nas listas de nosso estudo são muito escassas, mesmo se as compararmos com as poucas ocorrências que, por si só, refletem esses termos nas listas de disponibilidade de léxico publicadas até agora em outros pesquisas referentes a informantes pré-universitários.

3. Como é um processo dinâmico em andamento, o nivelamento lexical com o padrão se manifestará mais intensamente nos falantes mais jovens.

4. Por outro lado, as gerações mais antigas serão as mais leais ao léxico do dialeto, o que será evidenciado em uma aparência maior das variantes de dialeto em suas listas de disponibilidade de léxico.

5. Identificar as características sociais dos grupos que servem de refúgio para os elementos lexicais divergentes nos ajudará a desenvolver métodos de ensino de idiomas que facilitem a integração de estudantes em risco de exclusão social. Da mesma forma, a incorporação desses grupos sociais divergentes nos processos de ensino de idiomas (voluntários, fonte de documentação oral e experiência local) pode favorecer a inclusão social dos alunos mais expostos à exclusão.

A partir do objetivo geral de nosso estudo, expresso no início desta seção propôs objetivos específicos para corroborar as hipóteses anteriores:

1. Associar as formas dialetais encontradas nas listas de disponibilidade lexical da cidade de Málaga aos indivíduos que as produziram.

2. Procurar possíveis refúgios sociais onde as formas dialetais se mantenham como única forma de resistência contra a mudança convergente em andamento. Para isso, 
procederemos a realizar: a) o estudo da densidade de dialetalismos em nossas listas; b) a relevância quantitativa; e c) a comparação com o uso de seus equivalentes lexicais gerais.

\section{Contexto metodológico}

Conforme já citado, para realizar este trabalho, analisamos o corpus lexical que constitui o banco de dados do Projeto CONSOLEX. Este projeto analisa a variação social do léxico disponível dos falantes da cidade de Málaga, a partir de uma amostra estratificada uniforme $(\mathrm{n}=72)$. As variáveis pré-estratificação são idade, sexo e escolaridade. A tabela 1 mostra a distribuição da amostra:

Tabla 1 - Distribuição da amostragem

\begin{tabular}{|c|c|c|c|c|c|c|c|c|c|}
\hline \multicolumn{5}{|c|}{ Homem } & \multicolumn{5}{|c|}{ Mulher } \\
\hline Formação & 0 & 1 & 2 & Total & Formação & 0 & 1 & 2 & Total \\
\hline Idade & & & & & Idade & & & & \\
\hline $20-34$ & 4 & 4 & 4 & 12 & $20-34$ & 4 & 4 & 4 & 12 \\
\hline $35-54$ & 4 & 4 & 4 & 12 & $35-54$ & 4 & 4 & 4 & 12 \\
\hline$>55$ & 4 & 4 & 4 & 12 & $>55$ & 4 & 4 & 4 & 12 \\
\hline Total & 12 & 12 & 12 & 36 & Total & 12 & 12 & 12 & 36 \\
\hline
\end{tabular}

Educação: 0. Sem estudo ou ensino fundamental completo; 1. Ensino Médio Completo; 2. Ensino Superior Completo.

Fonte: Elaborado pelo autor

A metodologia utilizada para coletar e editar os materiais é a proposta pelo Projeto Lexical de Disponibilidade Pan-Hispânica (PPHDL), explicada em Ávila e Villena (2010).

A natureza dos trabalhos de disponibilidade lexical é simples: pressupõe-se que a consideração conjunta das listas individuais possa nos ajudar a construir o campo de experiência compartilhado pela comunidade estudada. As palavras que aparecem nas primeiras posições das listas formam o núcleo central de um vocabulário muito frequente em todos os falantes e de atualização imediata em cada centro de interesse. Nesse núcleo central, são desenhadas coroas sucessivas nas quais aparecem formas cada vez menos frequentes, menos compartilhadas e de atualização mais lenta. Isso produz a imagem de um subconjunto de vocabulário prototípico em cada campo da experiência (os conceitos mais próximos e acessíveis com as palavras mais frequentes) que todos os falantes conhecem e manipulam, mas também aponta para a existência de círculos concêntricos ao seu redor, onde coloca o léxico mais especializado ou mais preciso. Esse léxico menos prototípico, mas mais específico, sugere a posse, pelo indivíduo que o atualiza, de conceitos diferentes daqueles de 
domínio comum e/ou acesso a campos técnicos, científicos ou culturais somente ao alcance de uma parte dos falantes da comunidade. É precisamente nesses níveis em que presumivelmente encontramos a maioria dos dialetalismos em nossas listas associados a falantes com perfis sociológicos específicos: 1) indivíduos que, de uma maneira ou de outra, têm mais experiência no campo da cultura popular ou diretamente relacionados à área geográfica estudada; 2) indivíduos cujas características pessoais favorecem o aparecimento de dialetalismos em suas listas de disponibilidade lexical. Nesse caso, por exemplo, poderíamos encontrar sujeitos que, nos dois minutos disponíveis para atualizar suas listas para cada foco de interesse, escrevessem as palavras mais disponíveis antes de outros - ou seja, as mais prototípicas e compartilhadas por todos - e ter tempo depois para lembrar outras mais específicas ou, talvez, mais geograficamente restritas.

O banco de dados do Projeto CONSOLEX aparece estruturado em diferentes pastas ou diretórios $(\mathrm{N}=72)$, cada uma com um número que corresponde ao número com o qual os informantes são identificados (001 = informante número 1). Por sua vez, a estrutura de cada uma dessas pastas consiste em vinte arquivos de texto, um para cada campo de interesse ou estímulo com o qual trabalhamos $(01=$ campo de interesse 1$)$. Além disso, dispomos de um banco de dados sociológico, reticular e individual, composto por 72 arquivos, nos quais foram codificadas as características dos sujeitos estudados. Obviamente, o número de identificação de cada um dos arquivos sócio-reticulares corresponde novamente ao número de identificação de cada sujeito, tornando a associação subsequente entre bancos de dados sociológicos e lexicais extremamente confortável.

\section{Dialetalismos}

As importantes dificuldades relacionadas ao próprio conceito de "dialetalismo" ou "regionalismo" dificultam a atribuição do caráter de dialetal a uma palavra. Seguindo um critério restritivo, poderíamos considerar termos andaluzes como os típicos da Andaluzia que não existem ou apresentam diferenças claras com o espanhol geral. Assim, a tarefa de identificar andaluzismos em nosso corpus parece fácil se apenas recorrermos a consultas duvidosas no RAE Dicionário de Língua Espanhola (DLE) e em alguns dicionários andaluzes diferenciados que atendam aos critérios mínimos de confiabilidade.

A ausência de consenso e a enorme diversidade de características e valores apresentados pelos diferentes repertórios de dialetos é uma constante no trabalho lexicográfico. Muitos dos trabalhos realizados até o momento são obras de académicos 
eruditos e amadores sem critérios nem rigor lexicográficos; por vezes, muitos termos vulgares ou criados espontaneamente são incluídos nesses repertórios simplesmente porque não estão contidos no DLE. A principal preocupação de muitos desses autores é geralmente que os vocábulos que consideram típicos do local apareçam no dicionário oficial. No entanto, muito se discutiu sobre a conveniência ou não de incluir em um dicionário geral vocábulos de idiomas restritos a apenas um dos territórios representados pelo idioma que atribuído no título do dicionário. De fato, a presença de variantes regionais em dicionários gerais de 'provincialismos', como se chamavam no Dicionário de Autoridades, faz parte da tradição lexicográfica espanhola.

A distinção entre dicionários completos (com unidades da língua geral e suas variantes) e dicionários diferenciais (com unidades não registradas nos dicionários gerais) implica conceber os dicionários gerais como os responsáveis exclusivamente pelo idioma padrão ou idioma comum e, portanto, teriam que eliminar os detalhes técnicos e dialetalismos que hoje coletam. Mas isso dificilmente poderá ser realizado, dada a concepção tradicional do dicionário geral como uma expressão da maturidade cultural de um povo ou depósito da memória social.

A lexicografia regional peninsular trabalhou em tesouros diferenciais. A referência mais confiável realizada sobre as falas da comunidade estudada neste trabalho que pode nos indicar o caráter dialetal dos vocábulos usados pelos informantes do nosso projeto é o Tesouro Léxico das Falas da Andaluzia (TLHA).

Este Tesouro registra todas as vozes gravadas em qualquer um dos repertórios elaborados sobre a modalidade linguística do espanhol na Andaluzia. Este Tesouro atende a repertórios gerais e provinciais, locais, restritos ou específicos. Além disso, é considerado o léxico do dialeto registrado pelo Academic Dictionary (DLE, 1992) e pelo Vox Dictionary (VOX, 1987). Por fim, vale ressaltar que também inclui todo o vocabulário contido nos diferentes mapas do Atlas Linguístico e Etnográfico da Andaluzia (ALEA, 1991), acompanhando cada vocábulo à chave da localidade a que pertence. Em suma, para a elaboração do Tesouro Lexical dos Falantes da Andaluzia, foram reunidos 146 repertórios diferentes.

Os vocábulos de nossa base de dados serão considerados andaluzismos, em definitivo, se estiverem presentes neste Tesouro de andaluz. 


\section{Análise. Primeiras considerações}

A. Apenas 13 das 5.860 palavras que compõem as listas de léxico disponíveis para a cidade de Málaga são marcadas como dialetalismos de acordo com os critérios acima mencionados, o que representa uma porcentagem de 0,22 formas de dialetos sobre o corpus total. Esse número é insignificante e, de fato, se o compararmos com outros dados de estudos semelhantes realizados em outras áreas, é muito baixo, como pode ser visto na Tabela 2:

Tabela 2 - Comparação do número de dialetalismos coletados em diversos estudos

\begin{tabular}{|c|c|c|c|c|}
\hline $\begin{array}{c}\text { Aragón } \\
\text { (Arnal, 2008) }\end{array}$ & $\begin{array}{c}\text { Cádiz } \\
\text { (González, } \\
1992)\end{array}$ & $\begin{array}{c}\text { Castilla-La } \\
\text { Mancha } \\
\text { (Hernández, } \\
2006)\end{array}$ & $\begin{array}{c}\text { Gran Canarias } \\
\text { (Samper y } \\
\text { Hernández, } \\
2006)\end{array}$ & $\begin{array}{c}\text { Málaga } \\
\text { (Ávila y } \\
\text { Villena, } \\
\text { 2010) }\end{array}$ \\
\hline $280(3 \%)$ & $89(1,34 \%)$ & $162(1,27 \%)$ & $383(2,87 \%)$ & $13(0,22 \%)$ \\
\hline
\end{tabular}

Fonte: Elaborado pelo autor

B. Como em estudos anteriores, a presença de dialetalismos está registrada nos campos de interesse mais associados às tradições locais e ao ambiente em que a pesquisa é realizada: móveis da casa, alimentos, meios de transporte, brincadeiras e entretenimento, a cidade, O mar, A cozinha, Trabalho do campo e jardim e Escola. Em todos eles, no entanto, existe uma baixa densidade de dialetalismos, abaixo de 3\% em relação ao número total de palavras que compõem o centro de interesse em questão, como mostra a Tabela 3.

Tabela 3 - Densidade de dialetalismos em CONSOLEX

\begin{tabular}{|c|c|c|c|}
\hline $\begin{array}{l}\text { Campo de } \\
\text { interesse }\end{array}$ & $\begin{array}{l}\text { Número de } \\
\text { vocábulos }\end{array}$ & Presença de dialetalismos & $\begin{array}{c}\% \\
\text { de } \\
\text { dialetalismos } \\
\end{array}$ \\
\hline Móveis da casa & 194 & $\begin{array}{l}3 \\
\text { 'comodín' (mueble cómoda), 'descalzadora' } \\
\text { (descalzador), 'platero/mueble platero’ (mueble de } \\
\text { cocina para guardar platos). }\end{array}$ & 1,5 \\
\hline Alimentos & 313 & $\begin{array}{c}3 \\
\text { 'gazpachuelo' (sopa de pescado y mahonesa), 'pipirrana' } \\
\text { (ensalada de pescado), 'emblanco' (sopa de pescado). }\end{array}$ & 0,9 \\
\hline Jogos e diversão & 350 & 'patineta' (patinete), 'rueda' (corro), 'guiso' (rayuela). & 0,8 \\
\hline $\mathrm{O}$ mar & 452 & $\begin{array}{l}2 \\
\text { 'roqueo' (zona de rocas), 'moraga' (cena en la playa). }\end{array}$ & 0,4 \\
\hline $\begin{array}{l}\text { Meios } \\
\text { transporte }\end{array}$ & 177 & $\begin{array}{c}1 \\
\text { 'patineta' (patinete) } \\
\end{array}$ & 0,6 \\
\hline A cidade & 376 & $\begin{array}{c}1 \\
\text { 'patineta' (patinete) }\end{array}$ & 0,2 \\
\hline $\begin{array}{l}\text { Cozinha e seus } \\
\text { utensílios }\end{array}$ & 281 & 'platero/mueble platero' mueble de cocina para guardar & 0,3 \\
\hline
\end{tabular}




\begin{tabular}{|l|c|c|c|}
\hline $\begin{array}{l}\text { Trabalho do } \\
\text { campo e de } \\
\text { jardim }\end{array}$ & 254 & 'pasero' (lugar destinado a secar uvas) & 0,4 \\
\hline $\begin{array}{l}\text { A escola: móveis } \\
\text { e material }\end{array}$ & 284 & $\begin{array}{c}1 \\
0,3\end{array}$ \\
\hline
\end{tabular}

Fonte: Elaborado pelo autor

C. Como em outros trabalhos, a taxa de disponibilidade dos dialetalismos encontrados em nossas listas é muito baixa. Esse fato indica que o conjunto de dialetalismos analisados não é representativo da norma lexical presente na cidade de Málaga.

Na Tabela 4, classificamos as palavras de acordo com o centro de interesse em que elas aparecem. Eles são precedidos por um número que indica a posição em que esses termos aparecem em nossas listagens de disponibilidade. Após a palavra, entre parênteses, colocamos o número de informantes que a atualizam em suas listas. Na verdade, esta tabela nos ajuda a obter uma visão mais realista da verdadeira disponibilidade dos dialetalismos obtidos.

Tabela 4 - Grau de disponibilidade do dialetalismo CONSOLEX

\begin{tabular}{|l|l|c|}
\hline Campo de interesse & \multicolumn{1}{|c|}{ Vocábulo } & Índice de disponibilidade \\
\hline Móveis da casa & 65. 'Comodín' (3) & 0,01922 \\
& 105. 'Platero/mueble platero' (3) & 0,01111 \\
& 120. 'Descalzadora' (1) & 0,00860 \\
\hline Alimentos e bebidas & 174. 'Gazpachuelo' (2) & 0,01228 \\
& 261. 'Pipirrana' (1) & 0,00535 \\
& 312. 'Emblanco' (1) & 0,00195 \\
\hline A cozinha e seus utensílios & 55. 'Platero/mueble platero' (3) & 0,03242 \\
\hline A escola & 164. 'Piarda' (1) & 0,00845 \\
\hline A cidade & 345. 'Patineta' (1) & 0,00341 \\
\hline Trabalhos do campo & 143. 'Pasero' (2) & 0,00803 \\
\hline Jogos e diversão & 49. 'Rueda' (5) & 0,04803 \\
& 65. 'Guiso' (4) & 0,03261 \\
& 200. 'Patineta' (1) & 0,00914 \\
\hline Transportes & 40. 'Patineta' (8) & 0,03099 \\
\hline O mar & 177. 'Roqueo' (2) & 0,01296 \\
& 430. 'Moraga' (1) & 0,00345 \\
\hline
\end{tabular}

Fonte: Elaborado pelo autor

Em resumo, tendo em vista os resultados da Tabela 4, devemos concluir que 'comodín', 'platero', 'rueda', 'guiso' e 'patineta' são os dialetalismos mais conhecidos e comuns em nossas listas. Esse fato é reafirmado se observarmos que 'platero' e 'patineta' aparecem com o mesmo valor semântico em outros campos de interesse, embora em posições mais atrasadas e atualizadas por menos informantes.

D. A vitalidade desses 5 vocábulos imediatamente disponíveis - para aparecer nas 100 primeiras posições das listas de disponibilidade - pode ser calibrada comparando-as com os 
sinônimos existentes no espanhol geral. A Tabela 5 lista os 5 termos selecionados com seus respectivos equivalentes no espanhol padrão presente em nossas listas.

Tabela 5 - Dialetalismos CONSOLEX e seus equivalentes no espanhol geral

\begin{tabular}{|l|l|c|l|c|}
\hline $\begin{array}{l}\text { Campo de } \\
\text { interesse }\end{array}$ & Termo dialetal & Posição & Termo geral & Posição \\
\hline Móveis da casa & 'comodín' & 65 & 'cómoda' & 9 \\
\hline A cozinha & 'platero' & 55 & 'aparador' & 10 \\
\hline Jogos e diversão & 'rueda' & 49 & 'corro' & 260 \\
& 'guiso' & 65 & 'rayuela' & 96 \\
\hline Transportes & 'patineta' & 40 & 'patinete' & 15 \\
\hline
\end{tabular}

Fonte: Elaborado pelo autor

A preferência pela forma dialetal em relação à geral é mostrada em 'rueda' y 'guiso' . Ambos os termos demonstram uma clara tendência à denominação popular tradicional desses jogos na área estudada. Pelo contrário, eles estão claramente em desvantagem com o equivalente geral ‘comodín', 'platero' e 'patineta'.

\section{Distribuição social dos dialetalismos CONSOLEX}

Os poucos dialetalismos contidos nas listas de disponibilidade lexical da amostra estudada parecem encontrar refúgio nos grupos sociais mais antigos e naqueles com maior nível educacional. De fato, quanto mais se eleva as faixas etárias, mais dialetalismos encontramos, como observado no Gráfico 1; É provável que a maior experiência de vida constitua um fator determinante que justifique o conhecimento das formas dialetais, principalmente aquelas relacionadas a costumes populares - brincadeiras, diversões - ou objetos ou móveis presentes nas casas onde a infância foi passada.

O mesmo ocorre quando comparamos os níveis de escolaridade considerados: o gráfico 2 mostra que quanto maior o nível de instrução, maior a presença de dialetos; É provável que a metodologia que caracteriza os testes de disponibilidade lexical - listas fechadas limitadas por um tempo de elaboração - seja propícia para que os sujeitos com maior formação escrevam as palavras mais prototípicas e gerais, e, além disso, também tenham tempo para pensar sobre outras mais restritas ou específicas. De fato, as listas dos sujeitos mais instruídos são, em média, mais extensas que as demais. Portanto, eles têm mais oportunidade de acrescentar elementos menos acessíveis. Quando o número de elementos altamente acessíveis se esgota, começam a surgir palavras especializadas - frequentemente 
relacionadas à ciência e tecnologia - ou vinculadas à biografia individual - jogos infantis, à casa dos pais. -

Gráfico 1 - Distribuição dos dialetalismos. Idade.

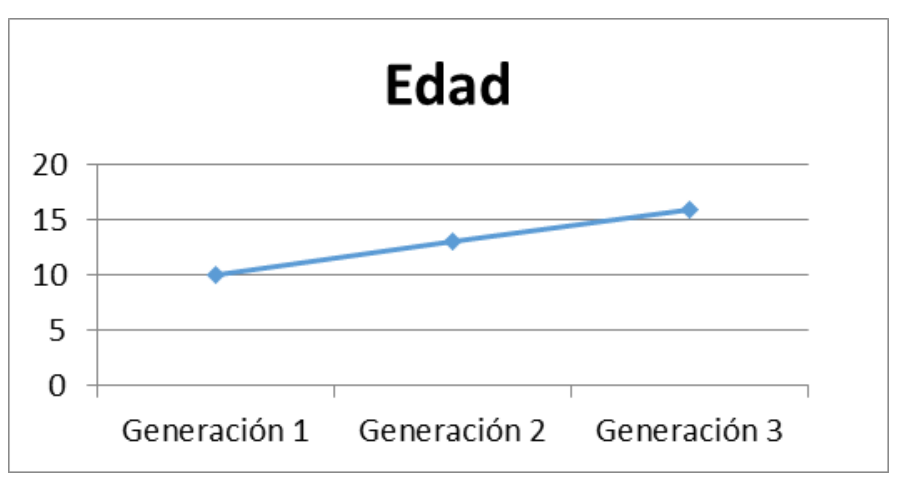

Fonte: Elaborado pelo autor

Gráfico 2 - Distribuição dos dialetalismos. Grau de instrução.

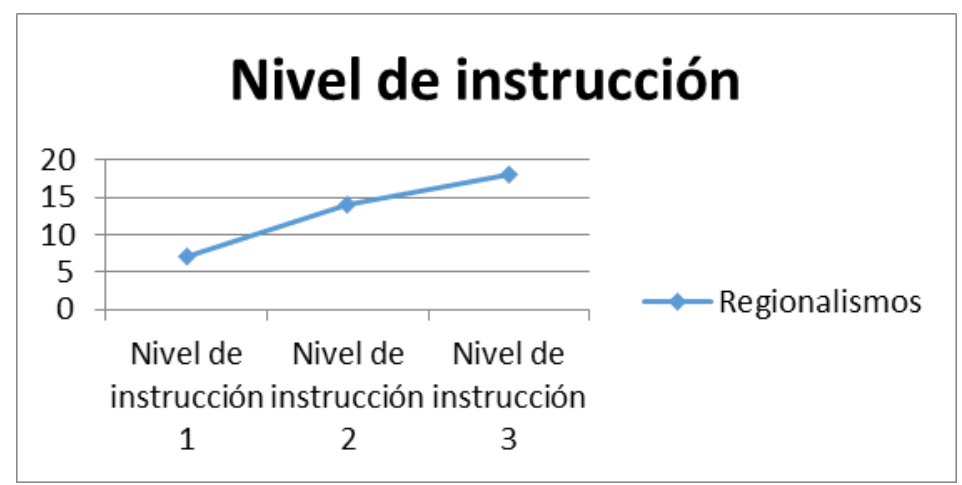

Fonte: Elaborado pelo autor

A distribuição de dialetalismos em relação ao sexo dos informantes também é impressionante. Embora seja verdade que nas palavras de maior extensão geográfica (regionais: 'comodín', 'descalzadora', 'gazpachuelo', 'moraga', 'patineta', 'pipirrana', 'platero'), não encontramos diferenças nesse sentido $(H=12, M=12)$, é curioso observar que as mulheres atualizam as palavras com a distribuição geográfica mais restrita (+ locais: 'emblanco' 'rueda/la rueda', 'guiso', 'piarda', $\mathrm{H}=3, \mathrm{M}=12$ ).

\section{Conclusões}

Nosso estudo corrobora o que foi apontado em outros estudos similares realizados em diferentes áreas geográficas: as listas de léxico disponíveis contêm poucas palavras de consideração dialética. Além disso, no nosso caso, esse achado se torna ainda mais evidente, 
pois as porcentagens de ocorrência desse vocabulário em nossas listas são consideravelmente inferiores às apresentadas em estudos anteriores.

Além disso, os poucos vocábulos encontrados refletem um baixo índice de disponibilidade e apresentam, em geral, uma clara desvantagem em relação às palavras equivalentes do espanhol geral (hipóteses 1 e 2). No entanto, a presença dessas poucas palavras em nosso corpus é por si só, significativa de várias maneiras quando observamos sua distribuição social:

1. Seu emprego é notavelmente baixo na população mais jovem. Os dados mostram que a presença desse tipo de léxico dialetal aumenta com a idade (hipóteses 3 e 4).

2. O maior nível de escolaridade dos informantes também parece favorecer o uso de dialetalismos (Hipótese 5).

3. Cada uma das palavras do dialeto consideradas tem seu próprio histórico. É curioso observar como os vocábulos relacionados a costumes e tradições históricas são atualizados em maior medida e por grupos sociais relacionados a determinadas atividades populares (Hipótese 5)

4. As mulheres tendem a atualizar as palavras locais mais em suas listas do que os homens. Estes geralmente estão relacionados a jogos tradicionalmente relacionados a mulheres e alimentos ou refeições (Hipótese 5).

Em resumo, ainda que as listas de disponibilidade lexical não favoreçam a presença de dialetos, podemos nos deparar com a observação de um fenômeno interessante: o léxico do dialeto passa por um processo de nivelamento semelhante ao de outros componentes linguísticos (Hipótese 1). É provável que a variação observada possa ser condicionada pela idade e escolaridade do falante e, possivelmente, pelo sexo dos informantes (Hipótese 5).

Em vista dos resultados obtidos, o perfil do falante nativo com o qual poderíamos trabalhar na sala de aula de estudantes estrangeiros em risco de exclusão seria uma mulher com idade avançada, com ensino médio ou superior completos e fortes raízes locais. Essas pessoas poderiam atuar como voluntárias na execução de tarefas para apoiar o professor de língua estrangeira a contribuir com toda sua experiência e conhecimento vernacular para o benefício de populações socialmente vulneráveis. Esses grupos poderiam se beneficiar do conhecimento acumulado ao longo dos anos na biografia pessoal desses voluntários para alcançar um maior grau de integração social. Em todo caso, dado o pequeno número de dialetalismos analisados, essas são hipóteses atraentes para serem corroboradas em trabalhos 
lexicográficos de natureza diferente daquela de disponibilidade lexical, onde a presença de dialetalismos é quantitativamente mais representativa.

\section{REFERENCIAS}

ARNAL, M. L. Los dialectalismos en el léxico disponible de los estudiantes aragoneses. In: ARNAL, M. L. (Ed.). Estudios sobre disponibilidad léxica en los jóvenes aragoneses. Zaragoza: Institución Fernando el Católico, p. 17-49, 2008.

ÁVILA, A. M. La utilidad del vocabulario dialectal en el aula de lenguas extranjeras. Propuesta de selección léxica basada en coronas concéntricas. MarcoELE: Revista de Didáctica Español Lengua Extranjera, n. 25, jul./dez. 2017a.

ÁVILA, A. M. Entre limonetis y malaguitas. Estudio del léxico divergente de proximidad. Nuevos datos del Proyecto CONVERLEX-Málaga. Hispania, v. 100, n. 4, p. 538-553, 2017 b.

ÁVILA, A. M. La integración sociocultural de los grupos vulnerables de migrantes desde el aula de lenguas. Propuesta de actuación desde la dialectología social en la ciudad de Málaga. Lengua y migración / Language and migration, v. 11, n. 1, p. 73-97, 2019a.

ÁVILA, A. M. Revisiting the Use of the Proximity Lexicon in the Classroom for Immigrant Populations at Risk of Social Exclusion: Does It Really Help? Languages, v. 4, n. 43, 2019b.

ÁVILA, A. M.; J. A. VILLENA. Variación social del léxico disponible en la ciudad de Málaga. Málaga: Sarriá, 2010.

BOURDIEU, P. Capital et marché linguistiques. Linguistische Berichte, n. 90, p. 3-24, 1984.

GONZÁLEZ, A. Disponibilidad léxica de los alumnos preuniversitarios de la provincial de Cádiz. Cádiz: Universidad de Cádiz, 1992.

HERNÁNDEZ, N. Hacia una teoría cognitiva integrada de la disponibilidad léxica: el léxico disponible de los estudiantes castellano-manchegos. Salamanca: Universidad de Salamanca, 2006.

SAMPER, J. A.; C. HERNÁNDEZ. Densidad de dialectalismos y condicionantes sociales en el léxico disponible de Gran Canaria. In: SEDANO, M.; BOLÍVAR, A.; SHIRO, M. (Coords.). Haciendo Lingüística. Homenaje a Paola Bentivoglio. Caracas: Universidad Central de Venezuela, p. 537-553, 2006.

SANKOFF, D. Sociolinguistic and Syntactic Variation. In: NEWMEYER, F. J. (Coord.). Linguistics: The Cambridge Survey. v. 4. Language: The Sociocultural Context. Nueva York: Cambridge University Press, p. 140-161, 1988.

VILLENA, J. A. Fundamentos del pensamiento social sobre el lenguaje. Málaga: Ágora, 1992. 
VILLENA, J. A. La formación del español común en Andalucía. Un caso de escisión prestigiosa. In: MARTÍN BUTRAGUEÑO, P.; HERRERA, E. (Coords.). Fonología instrumental: patrones fónicos y variación. México: El Colegio de México, p. 211-256, 2008.

VILLENA, J. A.; A. M. ÁVILA. Estudios sobre el español de Málaga. Málaga: Sarriá, 2012.

WILLIAMS, G. Sociolinguistics: a sociological critique. Londres y Nueva York: Routledge, 1992.

\section{Como referenciar este artigo}

ÁVILA MUÑOZDO, Antonio Manuel. Distribuição social do léxico dialético na cidade de Málaga. Reflexões sobre a utilidade do uso de dialetismos em sala de aula de línguas estrangeiras. Rev. EntreLínguas, Araraquara, v. 6, n. 1, p. 37-51, jan./jun., 2020. e-ISSN: 2447-3529. DOI: https://doi.org/10.29051/el.v6i1.13207

Submetido em: 30/07/2019

Revisões requeridas em: 30/08/2019

Aceito em: 30/11/2019

Publicado em: 06/01/2020 